\title{
THE ASSESSMENT ON ESP WRITING FOR FISHERY DEPARTMENT STUDENTS
}

\author{
Theresia Widihartanti \\ Hang Tuah University, Indonesia \\ theresia.wd@gmail.com
}

\begin{abstract}
The application of ESP for college students is very crucial since they are led to have skills that are apt with the needs of working environment. The learning using ESP method must be implemented using the well-designed assessment that will encourage fishery students to have high self-esteem to explore their experience in fishery world. To what extends that the assessment will be appropriate for the writing papers of fishery students? The research method used was classroom action research to elevate students' ideas and observation research that was conducted in the field since the activities conducted needed a series of events. There were some findings: 1) An apt topic had to be chosen; 2) An experience learned that supported the data; 3) The result of the series of activities that was reported; and 4) The application of scoring rubric based on the previous activities that assessed the final writing papers. The fishery department students as the subject of the research was in their fourth semester since they had to learned prior knowledge needed in fishery field.
\end{abstract}

Keywords: assessment, ESP writing, fishery department students

\section{INTRODUCTION}

English for Specific Purposes (ESP) has already implemented at Hang Tuah University, Surabaya for delivering the main materials of learning the subject of English. The result has proved to be successful since Fishery Department students enjoyed the method for all kinds of learning processes: they read, speak, write, listen, and present their presentation in different types of activities; and vocabularies and diction learned in the term of fishery fields. Thus, it is very crucial to lead students to have skills that are apt with the needs of working environment.

ESP itself in this research is used to deepen students' horizon in learning Fishery fields such as fish cultures, fish biotechnology, fish catching tools, and entrepreneurship. From those fields, the author focuses on the implementation of learning entrepreneurship since this field explores students competencies in dealing in exporting fish products and it is apt with the vision of the university that sharpens students' 'maritime edupreneurship' as its motto. Here, students are encouraged to deepen their skills in introducing the fish products, selling them, starting the individual effort to open the stalls, calculating the profit, reviewing the customers' opinion in 'like and dislike' questionnaires and with the guidance of the lecturers, they start selling in medium scale. The learning using ESP method must be implemented using the well-designed assessment that will encourage fishery students to have high self-esteem to explore their experience in fishery world.

Every activities conducted by the students must be assessed since the final result of learning English must be reported. Thus, the application of ESP for college students must be graded using the scoring rubric to minimize the lecturers' subjectivity. ESP Writing is applied to monitor students' ability in writing an essay for their mid-test and final test; 8 sentences and 14 sentences respectively. Since the skill of writing graded, the application of Brown's Writing Scoring rubric (2004:239) was 
applied.

The object of the research was the fourth semester students of Fishery Department of Hang Tuah University, Surabaya. They had already got the subject of English at their first semester, so in the fourth semester they directly applied their basic knowledge of English to support their oral presentation and essay writing. Due to the subject of Entrepreneurship, they conducted a selling strategy to prepare the oral presentation as their mid-test of the subject called English for Fishery.

The research question emerged was "To what extends that the assessment will be appropriate for the essay writing of fishery department students? The question needed more than two weeks to implement due to the series of activities conducted by the lecturer and the students especially on how to enhance students' ability in selling the fish products produced by the wives of fishermen located at Kelurahan Sukolilo Baru, Kenjeran, Surabaya as the largest producer of chips and snacks.

Using the combination of field observation and classroom action research on how to prepare the format of oral presentation as the report of the students' entrepreneurship experience and finding the correlation with their essay writing, the author attempted to assess the students' abilities on both skills for the fourth semester students of Fishery Department.

\section{LITERATURE REVIEW}

\subsection{ESP}

Robinson (1980: 5) states "ESP is thought to suggest special language that focuses on the purpose of the learner and refers to the whole range of language resources." Here, ESP is learned as a new method of learning English for other fields of study such as science or academic, vocational programs, etc. that are deeper than social themes. In addition, Robinson (1980:6) states,

"The purpose is to elaborate a successful performance in work. Thus, the students of ESP is learning English 'en route' to the acquisition of some quite different body of knowledge as set of skills"

It can be concluded, ESP is applied due to the needs in the working environment that needs four skills of language, but the skills must be apt with the situation happens. We cannot neglect that the students need deeper terms of words, sentence, language functions, etc. that will be very urgent used in their real life experience especially in working field.

The language skills must be enlarged to a variety usages of communication such as speech, write letters, attend meetings, etc., so the users can be 'on the same page" with others. Robinson (1980:20) states,

"The discourse analysis of ESP means the stretch of language to indicate structuring text. In ESP, this term is related to the rhetorical functions of description, definition, and classification, so the students will focus on texts, functions and linguistics realization, most particularly the verb forms. In addition, the students of ESP will communicate in communicative specific area in learning their speech and writing."

Thus, in summary, learning ESP is one of the ways to understand new horizon where we want to work, so we can use our new knowledge in a appropriate way to communicate with others.

\subsection{Language Assessment (Brown, 2004)}

Brown (2004:3) states that test is a method of measuring a person's ability, knowledge or performance in a given domain. Thus, it can be concluded that the assessment is very crucial to conduct since the lecturer needs to know the level of students' understanding on the subjects learned. In addition, Brown (2004: 6) states that formal assessment is exercises or procedures specifically designed to tap into a 
storehouse of skills and knowledge. It means that 'learning' English is not just a series of activities, but the students must recall all the experience in their speech and writing, and to measure it, the assessment must be done.

Oral presentation (Brown, 2004:179), as one of the ways to assess speaking ability is elaborated due to the marketing strategy conducted in this research. The written reports was in the form of power point presentation, and the lecturer uses the scoring evaluation paper that is assessed in excellent, good, fair and poor terms (Brown, 2004:180)

The author applied extensive writing (Brown, 2004:220) that was implemented by learning the structured format of writing (Introduction, Body and Conclusion parts; within 14 sentences) to expose the marketing strategy. At last, the writing holistic evaluation (Brown, 2004:239) was applied to minimize the lecturer's subjectivity.

2.3 Entrepreneurship

Pasaribu (2012:1) states that entrepreneurship means bravery and focus on meeting the needs and solving the problems of life independently. It means that when someone does entrepreneurship, he/she learns to be independent in fulfilling the needs of others by conducting many ways in providing goods or services. In addition, Pasaribu (2012:1) also states that entrepreneurs are people who think beyond and globally on products and services, so they provide merchandise for those who need it. They have an ability to create their own business, their own principles, and distinguished ways to meet the needs of the society so the products will have additional values based on limited economical resource management. It can be concluded that becoming an entrepreneurs is not an easy way because they have to observe the needs of the customers in detail, so they will implement correct strategies in giving services or selling the merchandise.

Pasaribu (2012:104) states some functions of marketing. In this research, the students applied two of them. They are:

a. Merchandising: an effort to make the products closer to the buyers so the products must be suitable for the needs of the buyers and must be promoted.

b. Purchasing: the sellers buy the products first from the original providers, and then the sellers sell the products with small profit.

Above functions were conducted by the students when they sold the chips or snacks from the original place of producer that went to the places where the customers buy, stay, or study since the students sold the snacks at the campus canteen, houses near home, or their working offices.

Moreover, Pasaribu (2012:111) states some blockages in marketing products such as controlled variables that are Products, Price, Place, Promotion; and the uncontrolled variables are Competition, Technology advances, demographic changes, policies on politics and government finance, natural resources, producers, retailers' policies, etc.

\section{METHODS}

The research method used was classroom action research to elevate students' ideas and observation research that were conducted in the field since the activities conducted needed a series of events. The series of events elaborated were:

a. The lecturer explained the flows of the activities, starting with understanding of the list of the prices of snacks in kilograms and the amount bought.

b. The students bought the products and giving freedom to do their own marketing strategy such as packing the products in grams, a number of pieces, etc. and asking them to sell it based on the group's decision (they did it in pairs).

c. The students reported the marketing result in the form of oral presentation. 
d. The lecturer assessed the performance using the Brown's holistic evaluation in Speaking.

e. The students learned to write an essay that consisted of 14 sentences.

f. The students wrote the essay within sixty minutes.

g. The lecturer assessed the writing paper using Brown's holistic evaluation (TWE).

The research object was the fourth semester students of Fishery Department of Hang Tuah University, located at Arief Rahman Hakim 150, Surabaya. They had taken the subject of Entrepreneurship, so they knew how to do marketing in real experience. The main data of the research were the scores of oral presentation and the scores of essay writing. Using Brown's holistic evaluation on Speaking and Writing, the data were analyzed to find its correlation, whether the scores of Speaking was related to the essay writing scores, and both scores were related to the entrepreneurship real life experience.

The data collecting techniques were;

a. Collecting the report of the students' selling strategy in the form of power point presentation

b. Assessing the report in the form of oral presentation using Speaking holistic evaluation

c. Making the tables of scores

d. Collecting the students' essay writing papers

e. Assessing the report in the form of oral presentation using Writing holistic evaluation

f. Making the tables of scores

g. Drawing the graph of both data collected.

h. Making the conclusion based on the spread of scores obtained.

The spread of the scores of Speaking and Writing drawn showed the linear shape that went up based on the real data analyzed.

\section{FINDINGS AND DISCUSSION}

There were some findings based on the research conducted. They were:

4.1 Chosen topic must be consistent with the real experience

Since the topic was Entrepreneurship, the students who had learned the subject of Entrepreneurship knew the strategies of marketing and they directly applied it in the series of activities. They discussed it in pair, conducted the strategy, reported it, and wrote their real experience in selling the product. Thus, the topic of "Three ways of marketing the fish product" was consistent with their experience in field when they sold the product within a week.

4.2 The previous experience on selling the fish products accelerated the supporting

data for essay writing.

The experience of selling the product was the main element of essay writing because the students didn't get the data by browsing the email on how to do marketing. They directly went to places that were crowded by the customers, and they directly changed the strategy if it was failed. In supporting the data on essay writing, the students reported the detailed ways on selling the products, from the preparation to the profit calculation. In ESP, the students used the terms of processed, sales, stalls, packs, profit, nutritious, raw materials, buy, fry, earn, hygienic, high pricellow price, damage products, and restock on their essay writing vocabulary. Therefore, the marketing experience not only supported in structuring 
logical thinking on how to market the products successfully, but also it could emerge the new terms in fishery field spontaneously.

4.3 The reported activities recalled the students' memory to write.

In dealing with the previous marketing experience, most of the students had their backup plan to minimize the loss, so they took all data and selected the most successful strategy on their essay writing. The failure in selling the products was reported in oral presentation, and they noted down the newest strategy conducted. The lecturer just gave a week to conduct the selling, and then, the students wrote their experience into the format of writing given. They were encouraged to use the new terms in fishery field or marketing field to put it into the essay writing. The time allotment was sixty minutes, so the students had to recall their memory in explaining the ways in selling the products. Thus, the good behavior from doing the marketing strategy, making notes on the detailed data of selling, changing the strategy when it is failed, reporting the result of marketing, and writing it down into a journal of selling activities can be formed to the students' mindset.

4.4 The scores of essay writing using the scoring rubric were equal to the scores of

the students' oral presentation

The correlation between the result of the experience, oral presentation and essay writing could be observed by the scores of measured activities such as speaking and writing. Table 1,2 and the graph below showed that students' writing data was from recalling the data of their oral presentation. Thus, when both skills were measured, the result was equal (the graph 1). It was proved that the real experience can trigger the memory and then the students could use it to another skill such as writing. Table 1 and 2 showed that the previous data from experiencing the marketing in field could be the crucial element in triggering students' memory to produce the best writing with detailed information.

Based on the findings above, there were some data that supported them. They were:

a. The scores of the oral presentation (conducted in a pair)

b. The scores of the essay writing (conducted individually)

c. The graph showing the correlation between both scores of Speaking and Writing.

Table 1. The Score of Presentation (Speaking)

\begin{tabular}{|c|c|c|c|c|c|}
\hline No. & Students A \& B & Score & No. & Students A \& B & Score \\
\hline 1 & An \& Ag & 75 & 4 & Mel \& Alf & 70 \\
\hline 2 & Nur \& Ed & 75 & 5 & $\mathrm{Bm} \& \mathrm{Riz}$ & 68 \\
\hline 3 & Ang \& Al & 70 & 6 & Yos \& Fer & 60 \\
\hline
\end{tabular}

Based on table 1, there were six groups in the class; the highest score was 75 and the lowest was 60. The highest scores were the group of An \& Ag, and the group of Nur \& Ed. The rest had fairly scores. Since they didn't have specific meeting on how to pronounce words in fishery field, they made errors, the lecturer rectified them, and the lecturer gave correct way in pronouncing the words. 
Table 2. The Score of the Essay Writing

\begin{tabular}{|c|c|c|c|c|c|}
\hline No & Students & Score & No & Students & Score \\
\hline 1 & An & 80 & 7 & Mel & 70 \\
\hline 2 & Ag & 70 & 8 & Alf & 70 \\
\hline 3 & Nur & 80 & 9 & $\mathrm{Bm}$ & 85 \\
\hline 4 & Ed & 85 & 10 & $\mathbf{R i z}$ & 68 \\
\hline 5 & Ang & 68 & 11 & Yos & 60 \\
\hline 6 & Al & 68 & 12 & Fer & 60 \\
\hline
\end{tabular}

Based on table 2, the score of oral presentation was mostry equal to the scores of essay writing (An, Ag, Nur, Ed, Ang, Al, Mel, Alf, and Riz).

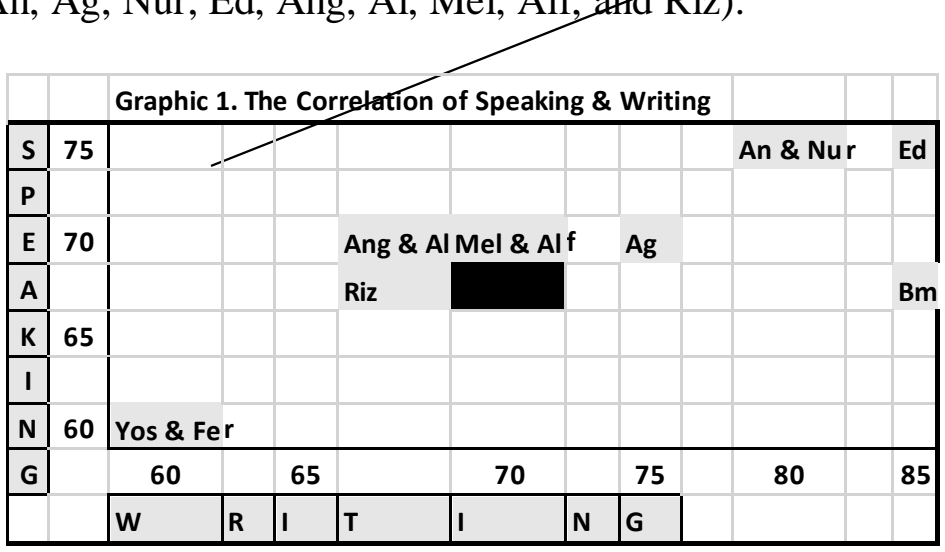

Based on the graph above, the scores of speaking supported the scores of writing since the spread of the students' scores was going up to the right position (pointed in the form of the arrow). It showed that the students' scores in speaking resulted a positive input to the result of their essay writing.

\section{CONCLUSION}

The assessment on ESP Writing for the Fishery Department students are an apt method in learning English especially if it is started with activities that accelerate students' skills such as real entrepreneurship experience reported as an oral presentation, and then it is followed by the writing skill itself. Thus, the students can recall their memories and enhance the assessment on their writing skill. This good behavior will be recalled on their last semester when they deal with finding data for their final writing paper. There are some crucial issues that can be learned from this research for the lecturer and the practitioner of ELT. They are:

a. Chosen topic must be consistent with the real experience

b. The previous experience on selling the fish products accelerated the supporting data for essay writing.

c. The reported activities recalled the students' memory to write

d. The scores of essay writing using the scoring rubric were equal to the scores of the students' oral presentation

To conclude, the assessment of ESP Writing using the preliminary activities such as conducting entrepreneurship experience can deepen students' skills so they are encourage to learn English more and more.

\section{REFERENCES}

Brown, H. Douglas. 2004. Language Assessment. New York: Pearson Education, Inc.

Pasaribu, H.Ali Musa.2012.Kewirausahaan Berbasis Agribisnis.Yogyakarta: Penerbit CV Andi 
Robinson, Pauline.2004. ESP (English for Specific Purposes). Canada: Pergamon Press Ltd.

\section{Appendices}

The example of power point presentation on oral presentation
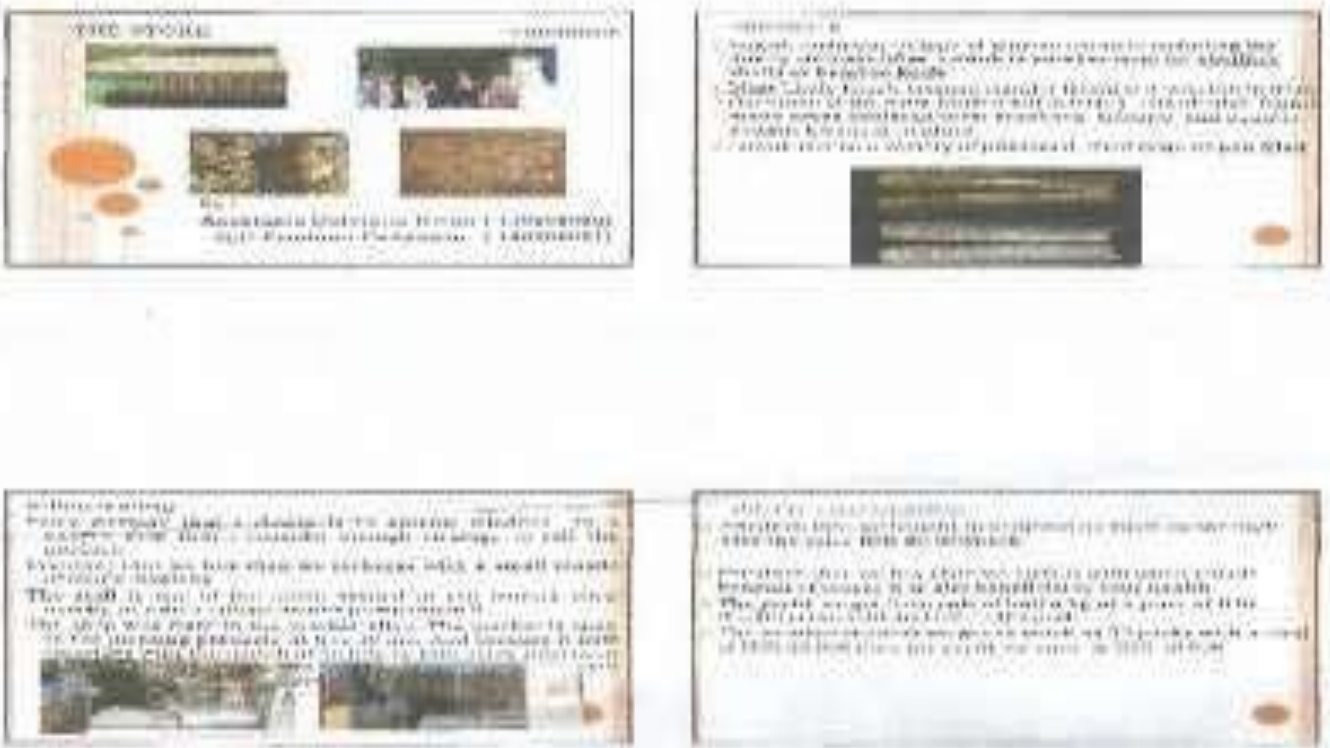


\section{The example of Essay Writing}

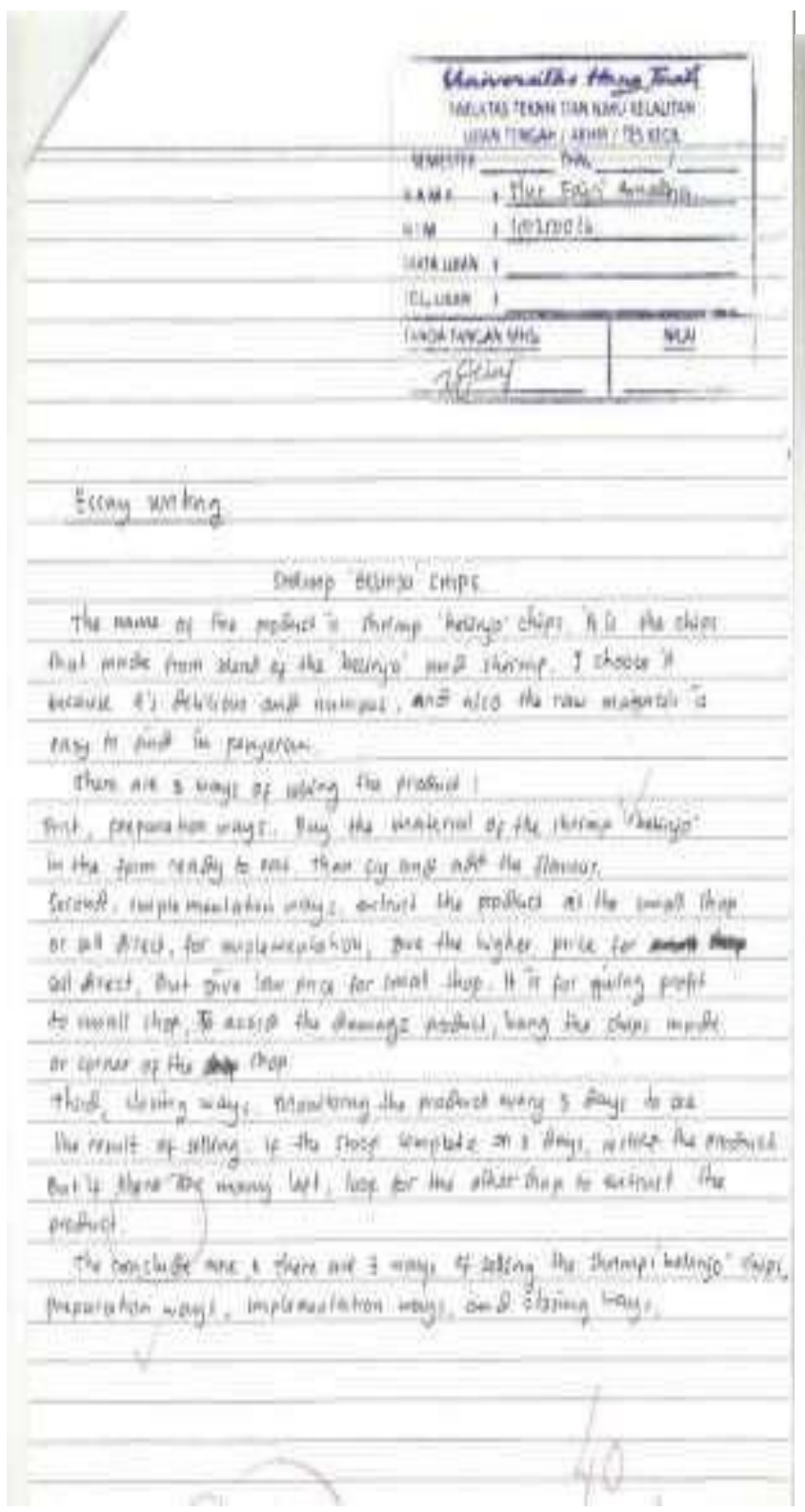

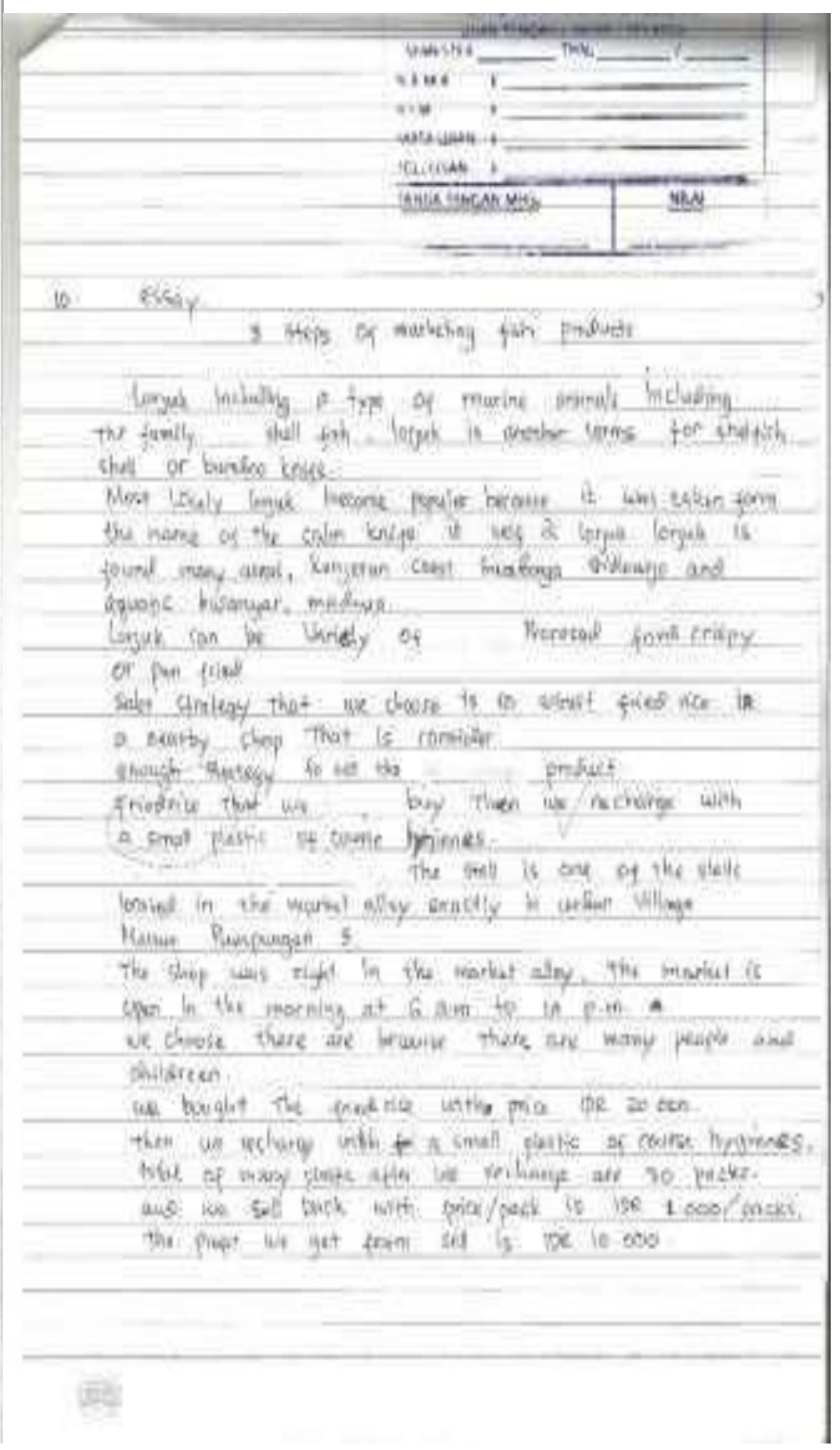

